Research Article

\title{
Field Monitoring-Based and Theoretical Analysis of Baota Mountain Landslide Stability
}

\author{
Yaming Tang $\mathbb{D}^{1}{ }^{1}$ Heping Shu, ${ }^{1}$ Qiang Xue, ${ }^{1}$ Jiayun Wang, ${ }^{1}$ Wei Feng, ${ }^{1}$ Hongna Ma, \\ Yan'e Li, ${ }^{1}$ Jin Luo, ${ }^{1}$ and Hamid Reza Pourghasemi ${ }^{2}$ \\ ${ }^{1}$ Xi'an Centre of Geological Survey, China Geology Survey, Xi'an 710054, China \\ ${ }^{2}$ Department of Natural Resources and Environmental Engineering, College of Agriculture, Shiraz University, Shiraz, Iran \\ Correspondence should be addressed to Yaming Tang; 1347607103@qq.com
}

Received 17 December 2020; Revised 4 March 2021; Accepted 11 March 2021; Published 23 March 2021

Academic Editor: Jian Xu

Copyright (C) 2021 Yaming Tang et al. This is an open access article distributed under the Creative Commons Attribution License, which permits unrestricted use, distribution, and reproduction in any medium, provided the original work is properly cited.

Landslide is one of the most widely distributed surface morphological landscapes, and it can cause a series of major economic and human losses. Field monitoring and limit equilibrium methods were applied to investigate Baota Mountain landslide stability, and soil volumetric water content, different scales of rainfall data, and landslide displacements were monitored using various equipment. The theoretical factor of safety was also calculated for the landslide. Finally, the theoretical results were validated by monitoring data in the field. The results demonstrate that soil volumetric water content experienced the greatest change with time at a depth of $0.2 \mathrm{~m}$ and then $1 \mathrm{~m}$; however, the change in soil volumetric water content was relatively small with time at a soil depth ranging from $2.0 \mathrm{~m}$ to $4.0 \mathrm{~m}$. Soil volumetric water content also did not change with time at a soil depth of $5.0 \mathrm{~m}$ and below. In addition, the retardation effect was found in different depths of volumetric water content for continuous rainfall. The safety factors were 2.713 and 1.133 for landslide No. 1 and landslide No. 2, respectively. These results indicate that landslide No. 1 is relatively stable, but there is a probability of the occurrence of movement in landslide No. 2. The monitoring displacement data indicate that landslide No.1 was in a relatively stable state between 2008 and 2013, and this result was in accordance with the value of theoretical calculation. This study provided relevant parameters for numerical simulation of landslides in loess areas.

\section{Introduction}

Landslides are one of the most widely distributed surface morphological landscapes and can cause a series of major economic and human losses [1-3]. Landslides also constitute the most important disaster type that can influence surface geomorphology processes $[4,5]$. Therefore, research that focuses on landslide stability is both significant and worthwhile $[6,7]$.

The landslide stability problem has been developed for evaluating the safety of hillslopes [8]. Some researchers studied and discussed current methods, which included physical models, field monitoring, and numerical analysis for slope stability analysis in detail [9-11]. When physical models were used to simulate slope stability, the soil structure usually changed during the construction of artificial slopes [12]. Some researchers also utilized field surveys and the freeze-thaw cycling theory to elucidate the mechanisms of natural and artificial slope failures in the Loess Plateau, China [13, 14]; however, these approaches cannot directly reflect the deformation processes of the landslide prototype. Subsequently, a series of pieces of equipment have been widely applied to monitor landslide displacement, which constitute direct and efficient ways to determine landslide stability and calculate its threshold, especially for single landslides $[15,16]$. Field monitoring of landslide stability from 2013 to 2016 in the Three Gorges Reservoir, China, was performed with different types of equipment, and the results demonstrated that landslide deformation reverted to seasonal stepwise cumulative displacements influenced by cycles of reservoir drawdown and rainfall [11]. It is worth noting that the monitoring data could be obtained each hour and in even shorter units of time. Tecca et al. (2003) applied various apparatuses to measure pore water pressure and volumetric water content for a landslide in Acquabona, Italy, and found that an 
instantaneous and vertically upward pore water pressure and volumetric water content were increased in a shallow slope [17]. Uhlemann et al. (2016) assessed ground-based monitoring techniques for landslide investigations in Hollin Hill landslides, UK, and demonstrated that the global positioning system (GPS) network of markers can offer a higher temporal and spatial resolution for landslide stability analysis [18]. Vassallo et al. (2020) implemented a system of inclinometers and GPS to determine landslide displacement in southern Apennines, Italy [19]. The above-mentioned achievements indicated that field monitoring and measurements are highly effective ways to obtain the stability of single landslides. However, monitoring of volumetric water content regarding landslide stability was performed relatively less frequently; in fact, volumetric water content is a key factor to analyze landslide stability [20]. With technological advancements, a large number of numerical methods were applied to calculate the stability of landslides. The basic approach is to determine a safety factor or stability threshold to prevent sliding failure of a given slope, but these methods vary markedly in simplification and accuracy [21, 22]. Meanwhile, conventional methods of slope analysis based on the concept of limit equilibrium have been broadly implemented, due primarily to their simplicity and applicability [8]. The main difference was in assumptions made about the shape of the slide surface (circular, plane, and logarithmic) for different limit equilibrium methods, and equilibrium equations were applied [9]. Subsequently, the slip surface would be divided into a series of slices with the process of computation, and the implemented limit equilibrium methods included simplified Bishop's, Janbu's, Spencer's, and Morgenstern-Price methods [22]. These methods are commonly employed to calculate the safety factor of slope stability in geotechnical engineering applications [23]. Zolkepli et al. (2019) used the modified Fellenius' and Bishop's methods to calculate the safety factor of slopes located at Pahang Matriculation College, Malaysia, and the results showed that the theoretical calculated values were highly similar to the monitoring data [24]. Limit equilibrium methods were also carried out to simulate the whole process of a landslide, particularly in the large deformation of soils during the landslide [22]. Above all, the values of landslide stability can be obtained conveniently by limit equilibrium methods.

The aim of this study is to determine the stability of Baota Mountain landslides for Yan'an City, Shaanxi Province, China. Field monitoring and limit equilibrium methods were used to study landslide stability, soil volumetric water content, and landslide displacements. In addition, the theoretical factor of safety was calculated for landslides. Finally, the different results were compared, and the theoretical results were validated by monitoring data. This study provided relevant parameters for numerical simulation of landslides in loess areas.

\section{Study Area}

2.1. Baota Mountain Landslide. Baota Mountain is located in the Baota District, Yan'an City, Shaanxi Province, in the northern of part of Xi'an City (Figure 1(a)). The study area is approximately $320 \mathrm{~m}$ long and $30-50 \mathrm{~m}$ wide and constitutes typical loess beam topography, which is surrounded by deep valleys and gulleys. In addition, Baota is located at the top of Baota Mountain (Figure 1(b)) and was built during the Tang Dynasty. Baota is $44 \mathrm{~m}$ high, with nine floors, and is a wellknown symbol of the historic Yan'an City.

There are two landslides (landslide No. 1 and landslide No. 2) on Baota Mountain. Landslide No.1 is distributed in the western part of the loess slope and is $85 \mathrm{~m}$ long from east to west and $95 \mathrm{~m}$ wide from north to south, and its main sliding direction is NW $65^{\circ}$. The maximum thickness of the landslide is approximately $20 \mathrm{~m}$, and its total volume is $9.4 \times 10^{4} \mathrm{~m}^{3}$. The elevation of the trailing edge of the landslide is $1,040 \mathrm{~m}$, and the escarpment of the trailing edge ranges from $1 \mathrm{~m}$ to $3 \mathrm{~m}$, within $2.5 \mathrm{~m}-4 \mathrm{~m}$ and $1 \mathrm{~m}-2 \mathrm{~m}$ in the north and south, respectively. Therefore, a concave slope with three sides of steep slope was formed, which exhibits typical landform characteristics of landslides. The shear outlet of the landslide is $974 \mathrm{~m}$, and the height of the slope is approximately $66 \mathrm{~m}$. The surface morphology of the landslide alternates with steep slopes and gentle slopes. Vegetation is comparatively better in the sliding area, especially in the middle of the landslide (Figure 1(c)).

Landslide No. 2 is distributed in the eastern part of Baota Mountain. It is a small landslide that was developed in loess areas. The elevations of the trailing and the leading edge are approximately $1,040 \mathrm{~m}$ and $1,015 \mathrm{~m}$, respectively, and the main sliding direction is NE $80^{\circ}$. The landslide is approximately $17 \mathrm{~m}$ long from east to west and approximately $25 \mathrm{~m}$ wide from north to south, and its total volume is approximately $975 \mathrm{~m}^{3}$. There are a series of steep walls in the three sides of the landslide (north, west, and south), within $1 \mathrm{~m}$ and $3 \mathrm{~m}$ high. An artificial retaining wall $2 \mathrm{~m}-3 \mathrm{~m}$ high is in the front of the landslide (Figure 1(d)). The soil mass of the landslide is fractured into pieces, and many fissures exist. Moreover, the vegetation is well developed on the landslide, and it is in a generally stable state. However, the slopes are becoming increasingly steep due to the construction of roads, which has led to a rising risk of local slides.

2.2. Geologic and Climatic Settings. The lithology of Baota Mountain is Jurassic sandstones underlying Quaternary loess, which are interspersed with lenticular sand-gravel layers of Early Pleistocene in the middle (Figure 2(b)). The maximum thickness of the Upper Pleistocene loess is $12.5 \mathrm{~m}$, among which the components of particles of the Upper Pleistocene loess are largely silt, and with a loose structure and large pores $[25,26]$. The maximum thickness of the Pleistocene loess is $63.6 \mathrm{~m}$, with relatively high clay content, and the average thickness of the loess is between $20 \mathrm{~m}$ and $30 \mathrm{~m}$. The thickness of Jurassic sandstone is relatively thick in the Yan'an region. The top surface of the basement rock of Baota Mountain is a pale-eroded terrain that slopes slightly northeast. There is no groundwater within $5 \mathrm{~m}$ below the bedrock surface.

The study area is located in the Northwest part of China, exhibits a semihumid and semiarid continental monsoon climate, and has a mean annual rainfall of $562 \mathrm{~mm}$. Rainfall 


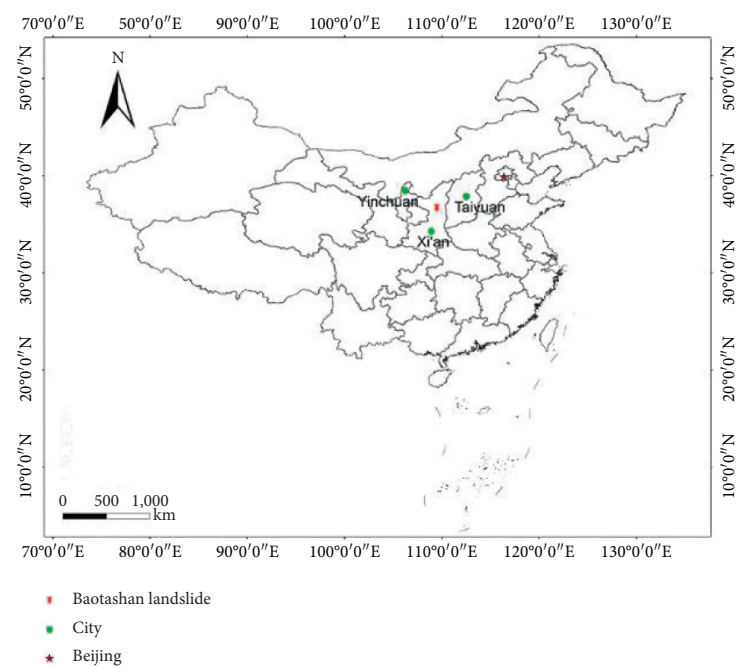

(a)

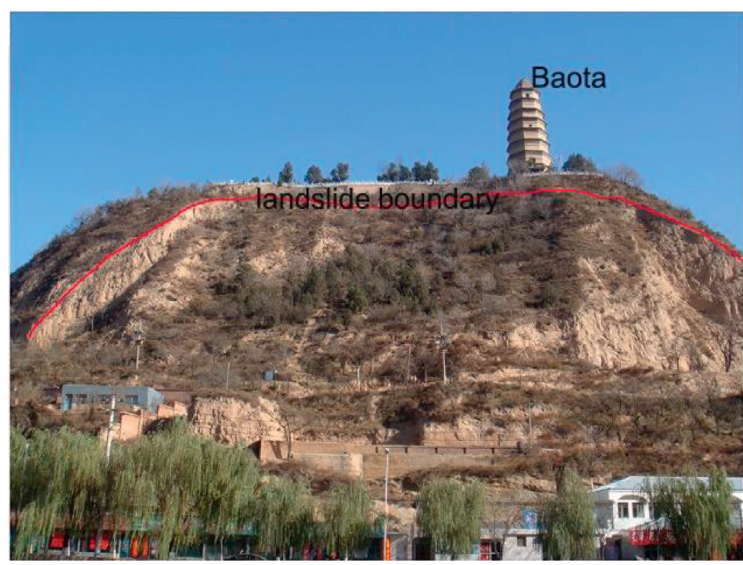

(c)

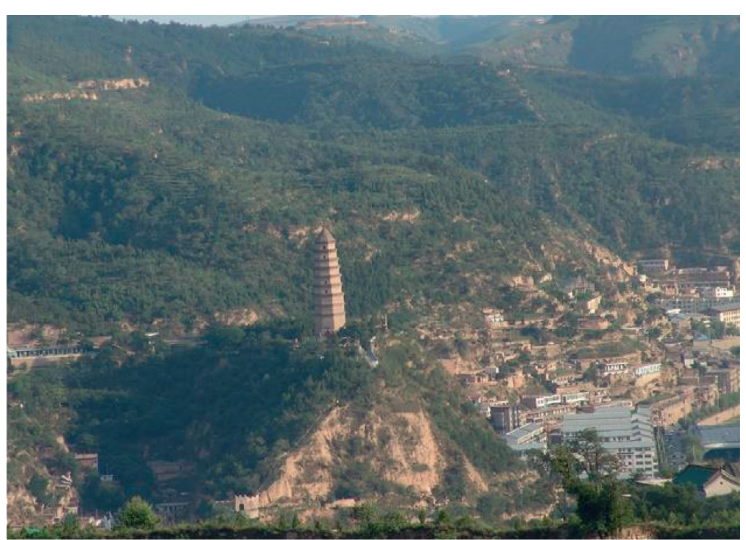

(b)

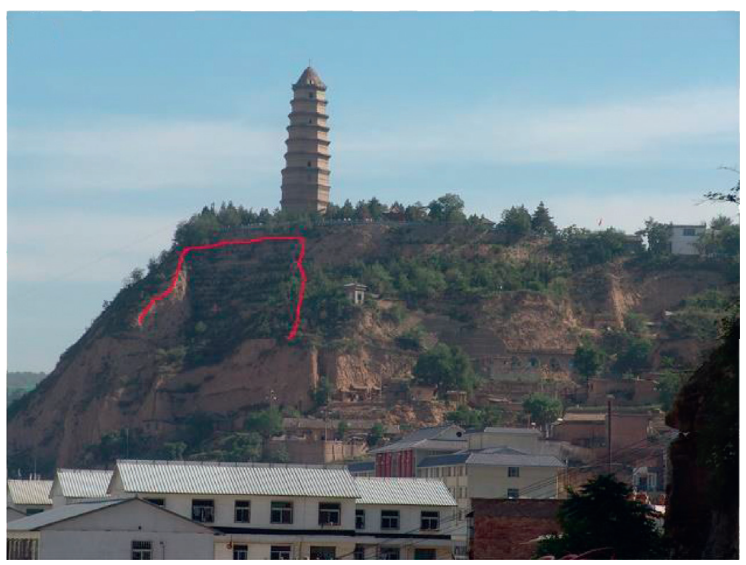

(d)

Figure 1: Study area: (a) location of the landslide in China; (b) landslide panorama; (c) landslide No. 1; (d) landslide No. 2.

mainly occurs in the period from June to September, accounting for approximately $70 \%$ of the total annual rainfall, and thundershowers occur frequently. Daily and hourly maximum rainfalls were observed in $1981(\sim 139.9 \mathrm{~mm})$ and $1979(\sim 62 \mathrm{~mm})$, respectively [27]. In addition, flash and prolonged heavy rainfall events often take place in the region, thereby triggering a series of geological disasters, especially landslides and debris flows.

\section{Methods}

The limit equilibrium method was selected to calculate landside stability [28], and field monitoring was applied to obtain landslide displacement. Subsequently, the results of theoretical calculation were validated by the results of field monitoring.

3.1. Theoretical Calculation of Landslide Stability. The limit equilibrium method is a crucial method to calculate the stability of landslides [29-31]. Although some theoretical shortcomings exist in this method, it has been improved after a series of researches [32, 33]. For example, the modified Bishop's method is slightly different from the ordinary method of slices in normal interaction forces in that the adjacent slices are assumed to be collinear and the resultant interslice shear force is zero [29]. The constraint introduced by normal forces in slices makes the problem statically indeterminate. As a consequence, iterative methods should be utilized to solve the factor of safety. The method has been shown to produce a safety factor within few percents of the "correct" values. $F_{s}$ for moment equilibrium in Bishop's method was given by Bishop (1955) [28]:

$$
F_{s}=\frac{\sum\left[c_{i}^{\prime} b_{i}+\left(W_{i}-u_{i} b_{i}\right) \operatorname{tg} \varphi_{i}^{\prime}\right] \zeta_{i}}{\sum W_{i} \sin \alpha_{i}+\sum Q_{i}\left(e_{i} / R\right)}
$$

where $F_{s}$ is the safety factor; $c_{i}^{\prime}$ is the cohesive force; $\varphi_{i}^{\prime}$ is the internal friction angle; $\alpha_{i}$ is the slope angle of the bottom of each slice; $b_{i}$ is the width of each slice; $W_{i}$ is the weight of each slice; $\mu_{i}$ is the water pressure at the base of each slice; $\zeta_{i}$ is the slice index; $e_{i}$ is the horizontal interslice force; and $R$ is the radius of the arc face.

The parameters were obtained from drilling data and experimental results, the specific parameters of which are presented in Table 1. 


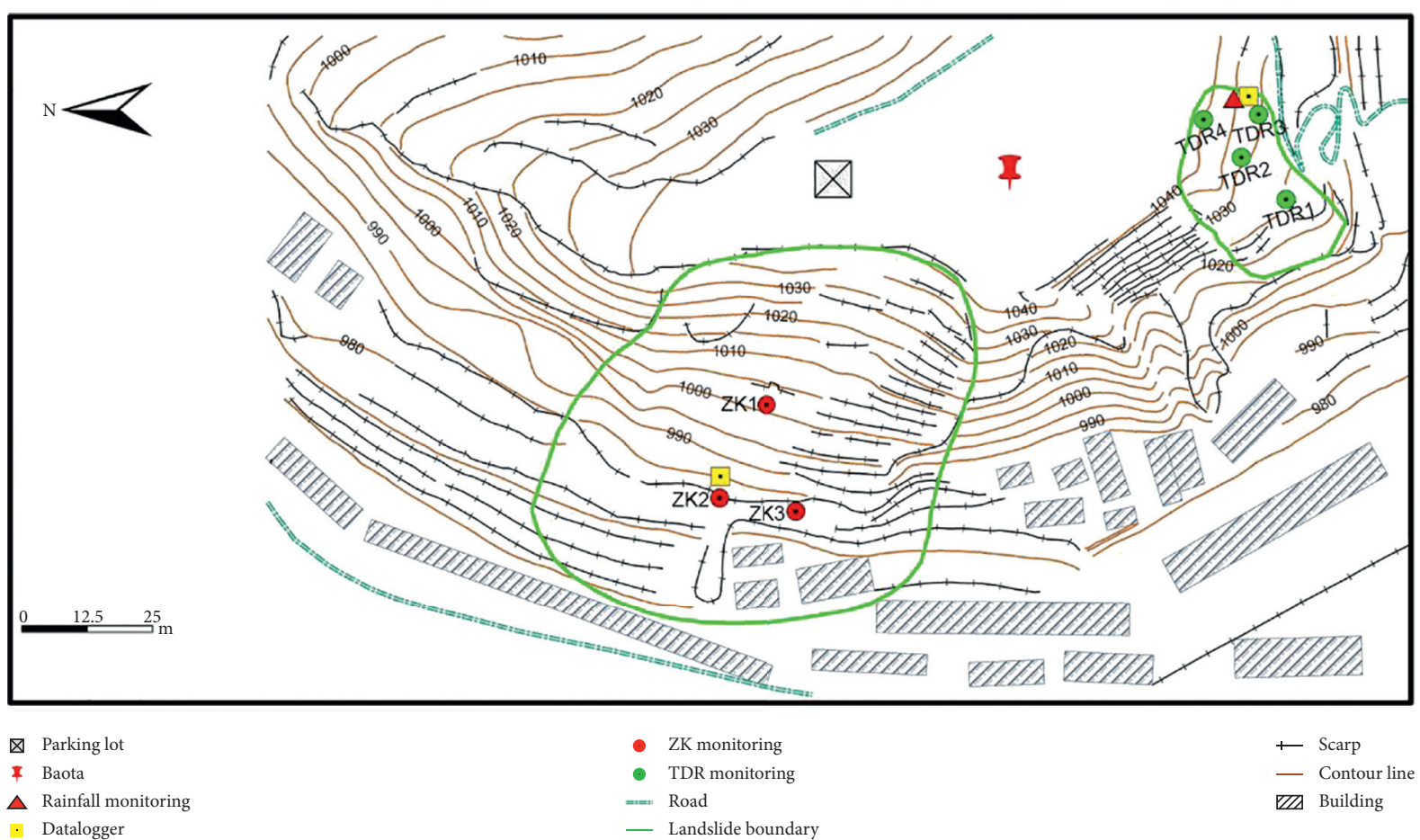

(a)

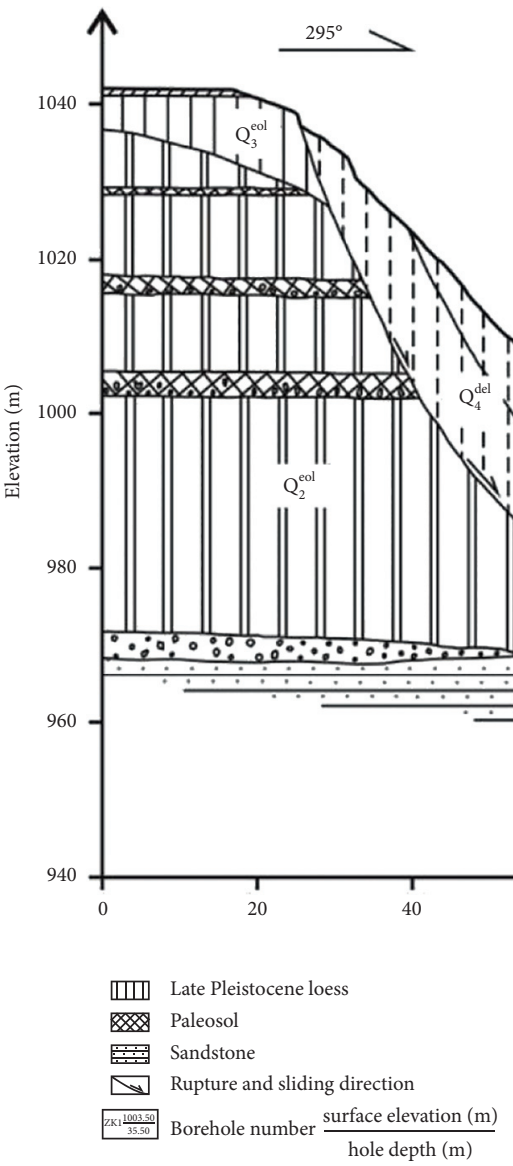

(b)

Figure 2: Continued. 


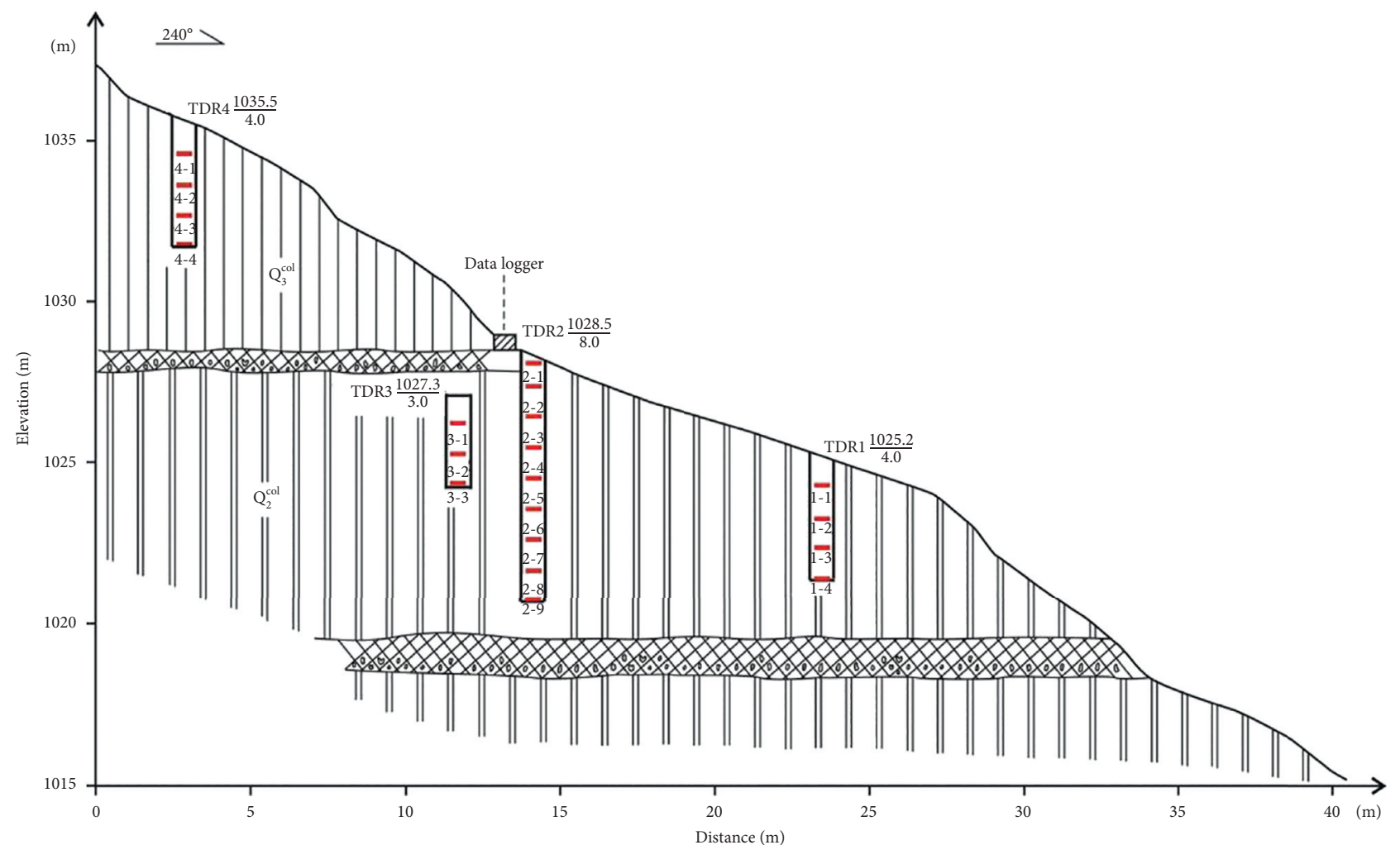

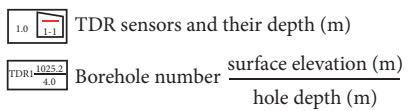

(c)

FIGURE 2: Schematic of monitoring system in Baota Mountain landslide and vertical section of boreholes with monitoring sensors: (a) schematic of monitoring system in Baota Mountain landslide; (b) distribution of ZK; (c) distribution of TDR.

Table 1: Parameters for landslide No. 1 and landslide No. 2.

\begin{tabular}{|c|c|c|c|c|c|c|}
\hline \multirow[t]{2}{*}{ Soil type } & \multicolumn{2}{|c|}{ Density $\left(\mathrm{kN} / \mathrm{m}^{3}\right)$} & \multicolumn{2}{|c|}{ Cohesive force $(\mathrm{kPa})$} & \multicolumn{2}{|c|}{$\begin{array}{l}\text { Internal friction angle } \\
\left(\left(^{\circ}\right)\right.\end{array}$} \\
\hline & No. 1 & No. 2 & No. 1 & No. 2 & No. 1 & No. 2 \\
\hline $\mathrm{Q}_{2}$ & 17.1 & 17.6 & 50 & 76.2 & 32 & 18 \\
\hline $\mathrm{Q}_{3}$ & 15.3 & 15.6 & 40 & 30.1 & 28.1 & 23.2 \\
\hline $\mathrm{Q}_{4}$ & 13.6 & - & 26 & - & 24.0 & - \\
\hline Ancient soil & 20.36 & 20.36 & 66 & 48.7 & 36.1 & 22.8 \\
\hline Medium-coarse sandstone & 22.1 & - & 1000 & - & 45 & - \\
\hline
\end{tabular}

The GEO-SLOPE module of GeoStudio software (http:// softwaretopic.informer.com/geostudio-software-for-mac/), which embedded the Bishop method, was carried out to calculate slope stability. The height was approximately $103 \mathrm{~m}$ and $22 \mathrm{~m}$ for landslide No. 1 and landslide No. 2, and their width was approximately $200 \mathrm{~m}$ and $40 \mathrm{~m}$, respectively. The soil types of landslide No. 1 were Late Pleistocene soil $\left(\mathrm{Q}_{3}\right)$, Holocene $\left(\mathrm{Q}_{4}\right)$ soil, ancient soil, Middle Pleistocene $\left(\mathrm{Q}_{2}\right)$ soil, and medium-coarse sandstone from the top to the bottom of landslide No. 1, respectively. The soil types of landslide No. 2 were $Q_{3}$, ancient soil, $Q_{2}$, ancient soil, and $\mathrm{Q}_{2}$, medium-coarse sandstone from the top to the bottom of landslide No. 2, respectively. The minimum depth of the sliding surface was set to approximately $0.1 \mathrm{~m}$ for both landslide No. 1 and landslide No. 2, the number of soil bulks was 100 , and the maximum number of convergent iterations was 5,000. The boot range of the sliding surface was set at the top loess layer of $\mathrm{Q}_{3}$ and $\mathrm{Q}_{4}$, and the range of roll-out was set at the foot loess layer of $\mathrm{Q}_{4}$ for landslide No. 1. With respect to landslide No. 2, the sliding surface was distributed in the top loess layer of $\mathrm{Q}_{3}$, and the range of roll-out was set at the foot of the loess layer of $\mathrm{Q}_{2}$. Groundwater was not considered in the process of slope stability calculation.

3.2. Field Monitoring. An integrated monitoring system was built and installed during the test pile construction. The monitoring system comprised displacement monitoring 
stations, and soil volumetric water content, inclinometers $(\mathrm{ZK})$, soil volumetric water content sensors (TDR) in the boreholes, and rain gauges were fixed to the test piles (Figure 2). The monitoring system consisted of displacement monitoring stations and a soil volumetric water content monitoring system, which includes inclinometers (ZK) and soil volumetric water content sensors (TDR) in the boreholes, and rain gauges were fixed to the test piles.

In 2007, three displacements monitoring sensors (ZK) were installed in landslide No. 1 (Figure 2(a)), the specific information for which is shown in Table 2 and Figure 2(b). The resolution of the equipment was $0.015 \mathrm{~mm} / \mathrm{h}$, and the monitoring period was from September 2008 to May 2013. Eight soil volumetric water content sensors (TDR) were fixed in landslide No. 2 (Figure 2(a)), the detailed information of which is presented in Table 2 and Figure 2(c). The error of TDR was less than $3 \%$, and the monitoring data were taken from October 2008 to March 2013. Rainfall gauges were installed on landslide No. 2, and the diameter of the measuring cylinder was $20 \mathrm{~cm}$. The rainfall monitoring period was from October 2008 to March 2013.

\section{Results and Discussion}

\subsection{Volumetric Water Content (VWC)}

4.1.1. Hourly Soil Volumetric Water Content. Figure 3(a) shows the relationship between VWC and daily rainfall from October 2008 to March 2013, and the trends of VWC were similar in different years. Specific examples are shown in Figures 3(b) and 3(c). The results of changes conformed to the natural phenomena, which indicated that the data were relatively reliable. The monitoring data of TDR 2-1 gradually increased during heavy rainfall, and the increase of VWC was earlier when heavy rainfall became greater. The monitoring data of TDR4-1 are shown in Figure 3(a). The VWC was at its maximum value among all monitoring points, because TDR4-1 was located at the top of landslide No. 2. The VWC of TDR 2-1 is shown in Figure 3(b). The soil VWC increased after $5 \mathrm{~h}$ of rainfall; however, the soil VWC of TDR 2-1 increased from $2 \mathrm{~h}$ after the end of the rainfall (Figure 3(c)), indicating that the changes of VWC were delayed in response to rainfall.

4.1.2. Daily Soil Volumetric Water Content. The daily change in soil VWC in different monitoring points of landslide No. 2 is presented in Figure 4. This monitoring was representative in loess regions, because the monitoring point of VWC was distributed in a natural slope [34]. The soil VWC was obviously affected by daily rainfall when the soil depth ranged from $0 \mathrm{~m}$ to $1 \mathrm{~m}$ (Figure 4); however, the VWC was stable when the soil depth was more than $2 \mathrm{~m}$. In addition, the VWC of surface soil $(0.2 \mathrm{~m})$ was slightly increased when the daily rainfall was greater than $10 \mathrm{~mm}$, but the VWC was unchanged in the soil depth of $1 \mathrm{~m}$. The VWC obviously increased above the soil depth of $1 \mathrm{~m}$ when daily rainfall reached up to $50 \mathrm{~mm}$, but the VWC was stable at the soil depth of more than $2 \mathrm{~m}$.
Continuous rainfall was selected as the research object. Using monitoring data from 28 August to 26 September, the retardation effect concerning different soil depths of VWC for rainfall was analyzed. The correlation coefficient between VWC and rainfall reached a maximum in the soil depth of $0.2 \mathrm{~m}$ after rainfall occurred for approximately $16 \mathrm{~d}$ (Figure 5). With respect to the soil depth of $1 \mathrm{~m}$, the correlation coefficient achieved the maximum when rainfall occurred for approximately $24 \mathrm{~d}$.

4.1.3. Monthly Soil Volumetric Water Content. The relationship between monthly rainfall and VWC was constructed based on the results of the hourly and daily monitoring data. The VWC increased with the increasing of rainfall, and the retardation effect still occurred. In addition, dissimilarities of the VWC peak in different years were obvious (2008-2013). For example, the maximum peak of VWC occurred in August and September in 2009 and 2010, respectively. Dramatic differences of the soil VWC were also evident for different monitoring points and soil depths (Figure 6). The results demonstrated that the changing of soil VWC was more obvious for soil depth, which was relatively lighter with increasing rainfall. However, the changing in soil VWC was relatively stable for relatively deeper soil depth. Meanwhile, the VWC was affected by rainfall at the soil depth of $0.2 \mathrm{~m}$, and a positive correlation relationship was obvious. The correlation coefficient, however, gradually decreased with increasing soil depth.

4.1.4. Volumetric Water Content in Different Soil Depths. The changing trends of VWC were essentially the same under different times and different soil depths on the monitoring point (Figure 7). The VWC fluctuated at different soil depths on the TDR2 monitoring points, and there were three wave peaks in the soil depths of $0-8 \mathrm{~m}$, which were distributed in the $3.0 \mathrm{~m}, 5.0 \mathrm{~m}$, and $7.0 \mathrm{~m}$ soil depths, respectively. Furthermore, the changing situation of soil VWC could be summarized based on the monitoring results. The largest change of soil VWC with time occurred at the depth of $0.2 \mathrm{~m}$ and then $1 \mathrm{~m}$. However, this change of soil VWC was relatively small with time at the soil depth ranging from $2.0 \mathrm{~m}$ to $4.0 \mathrm{~m}$, and the VWC did not change with time at the soil depth of $5.0 \mathrm{~m}$ and below.

These results indicated that the soil VWC was obviously influenced by rainfall, especially in the surface soil, and these results were in accordance with extant literature. [35-37] In addition, a series of cracks were found on the Baota Mountain (Figure 8). These cracks would provide an advantageous channel for rainfall infiltration, resulting in an acceleration of the rate of rainfall infiltration and ultimately forming underground runoff [38]. This would also provide a conducive condition for the occurrence of landslide disasters. Indeed, a large number of investigations have reported that such channel can impart a marked effect on slope stability, thus leading to the occurrence of landslide disasters under the induction of rainfall $[39,40]$. Consequently, the probability of a landslide in landslide No. 2 was relatively large. 
TABLE 2: Distribution of TDR (landslide No. 2) and ZK (landslide No. 1) monitoring system.

\begin{tabular}{|c|c|c|c|c|c|c|c|c|c|c|c|}
\hline Number & & & & & & & & TD & & & \\
\hline & $1-1$ & $1-2$ & $1-3$ & $1-4$ & $2-1$ & $2-2$ & $2-3$ & $2-4$ & $2-5$ & $2-6$ & \\
\hline Depth (m) & 1.0 & 2.0 & 3.0 & 4.0 & 0.2 & 1.0 & 2.0 & 3.0 & 4.0 & 5.0 & \\
\hline Number & & TDR2 & & & TDR3 & & & & TDR & & \\
\hline & $2-7$ & $2-8$ & $2-9$ & $3-1$ & $3-2$ & $3-3$ & $4-1$ & $4-2$ & $4-3$ & $4-4$ & \\
\hline $\begin{array}{l}\text { Depth (m) } \\
\text { Number }\end{array}$ & 6.0 & 7.0 & $\begin{array}{c}8.0 \\
\text { ZKI }\end{array}$ & 1.0 & 2.0 & 3.0 & $\begin{array}{l}1.0 \\
\mathrm{ZK} 2\end{array}$ & 2.0 & 3.0 & $\begin{array}{l}4.0 \\
\text { ZK3 }\end{array}$ & \\
\hline & $1-1$ & $1-2$ & $1-3$ & $1-4$ & $1-5$ & $2-1$ & $2-2$ & $2-3$ & $3-1$ & $3-3$ & $3-3$ \\
\hline Depth (m) & 10.7 & 14.0 & 19.5 & 25.5 & 34.4 & 3.7 & 9.2 & 10.9 & 5.75 & 11.15 & 14.05 \\
\hline
\end{tabular}

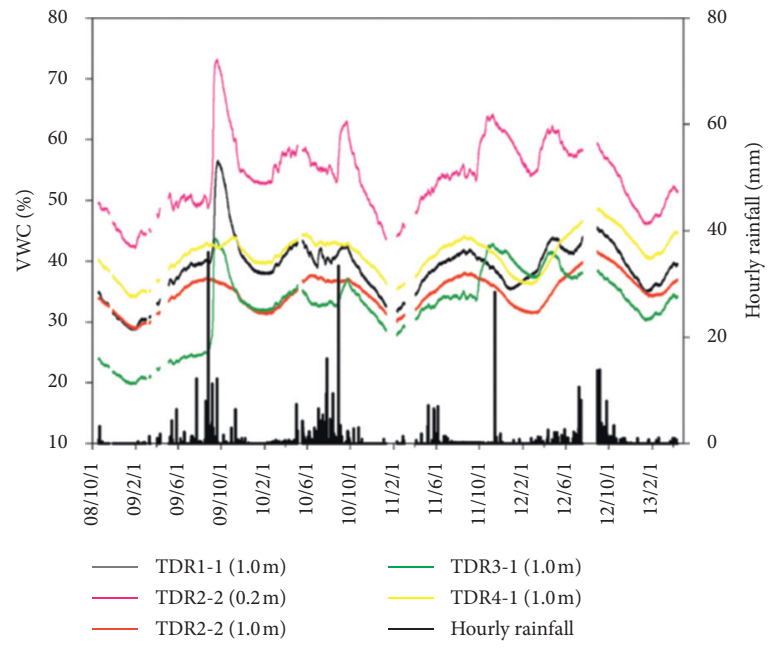

(a)

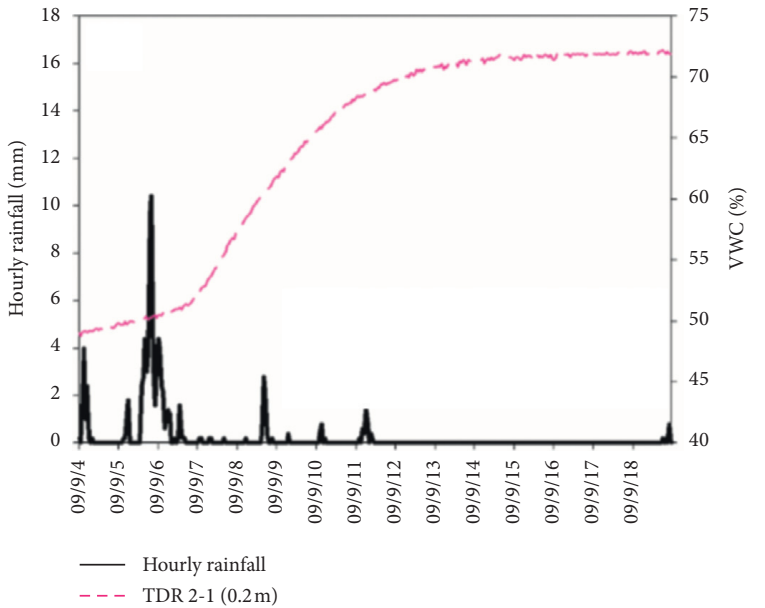

(b)

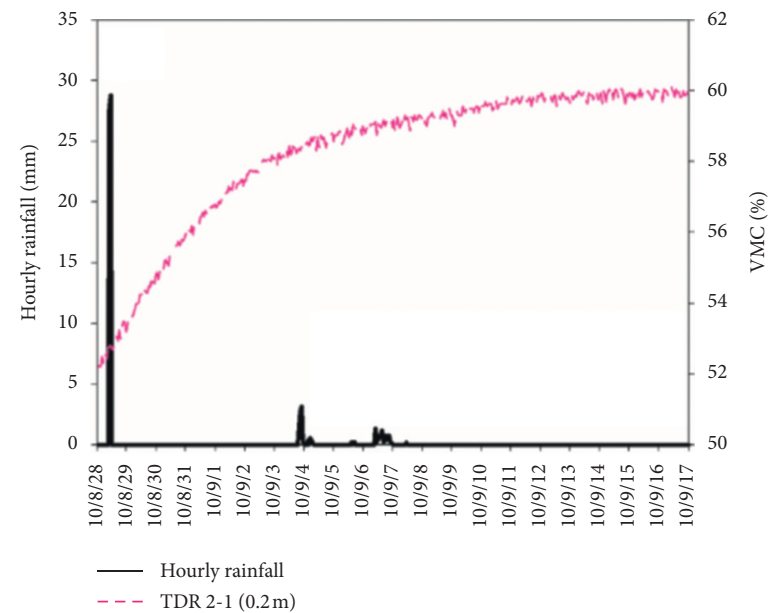

(c)

FIGURE 3: Relationship between VWC and rainfall per hour: (a) changing of VWC on the surface soil; ((b, c)) specific examples.

\subsection{Landslide Stability}

4.2.1. Theoretical Calculation Results. The Fs are 2.713 and 1.133 for landslide No. 1 and landslide No. 2, respectively (Figure 9). Landslide No. 1 is relatively safe based on the division standard of Fs [41]; however, landslide No. 2 is comparably instable. This result is consistent with the results of Section 4.1, in which the probability of a landslide in landslide No. 2 with continuous rainfall or heavy rainfall is relatively large. Salmasi et al. (2019) investigated the relationship between soil material parameters (i.e., cohesive force, internal friction angle, soil specific weight, and constant slope height) and safety factor. The results showed that cohesive force and internal friction angle impart an obvious effect on the safety factor, and this safety factor gradually decreased with the slow diminishing of cohesive force and 


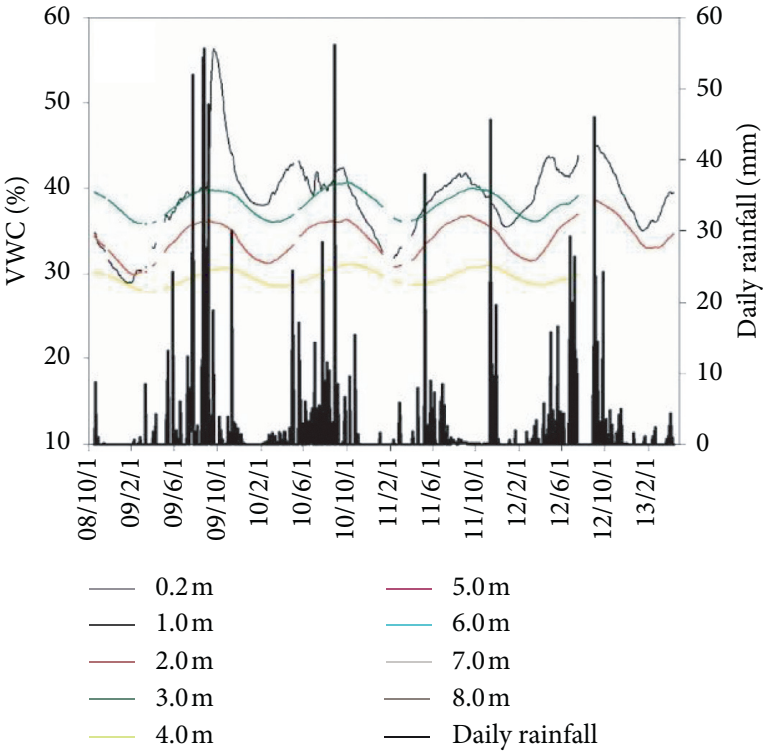

(a)

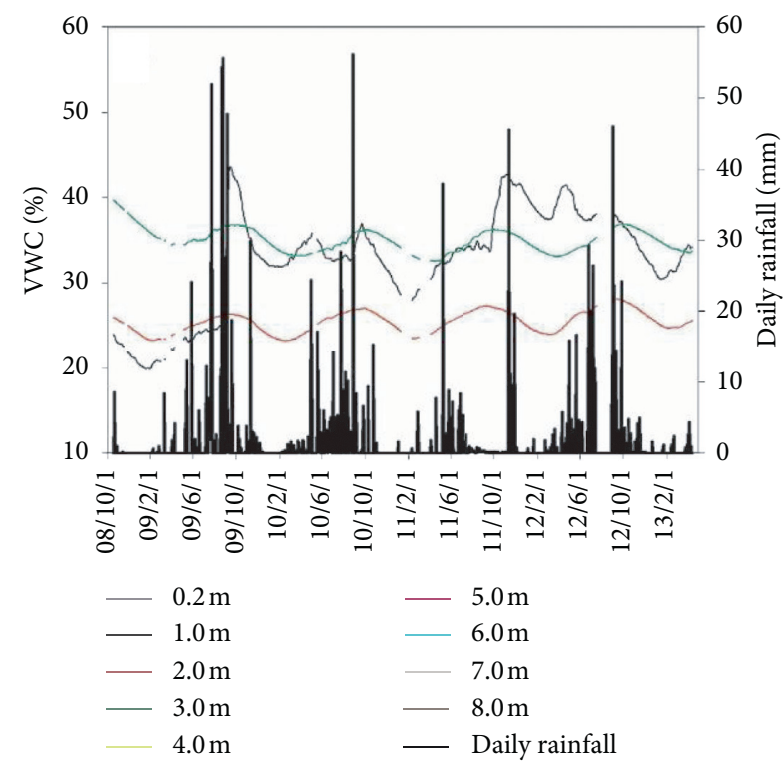

(c)

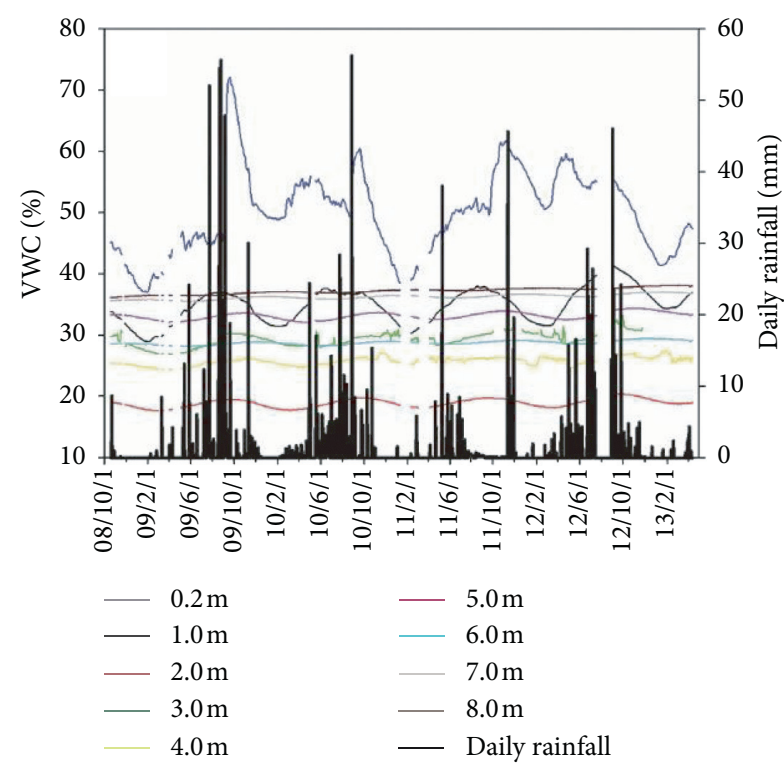

(b)

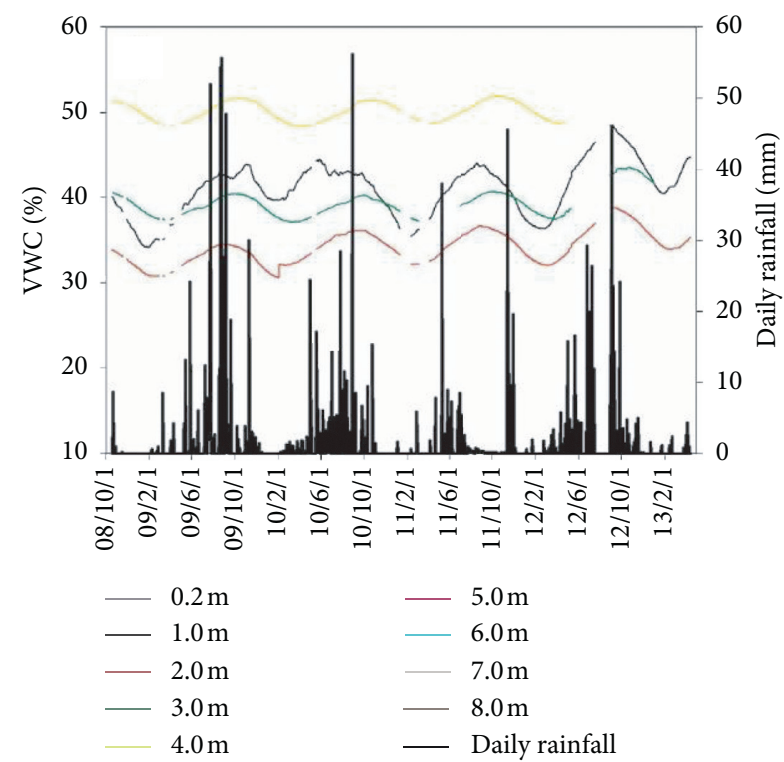

(d)

FIgURE 4: Relationship between daily soil VWC and rainfall: (a) TDR1; (b) TDR2; (c) TDR3; (d) TDR4.

internal friction angle [42]. In this study, the values of cohesive force and internal friction angle in landslide No. 1 were apparently higher than those of landslide No. 2, and thus the Fs was different.

\subsubsection{Monitoring Displacement Results}

(1). Different Monitoring Points Displacement. Overall, the landslide displacement was almost $0 \mathrm{~m}$ in different monitoring points based on the daily and monthly field monitoring data (Figures 10 and 11) in landslide No. 1; and a small-level displacement occurred in part of the monitoring points, with displacement values of less than $0.05 \mathrm{~mm}$.
Furthermore, landslide displacement was generally unaffected by daily rainfall (Figures 10 and 11). These results indicated that landslide No. 1 is in a relatively stable state, which was congruent with the theoretical calculation results.

(2). Different Depth Displacement. In general, the changing trends of displacement were essentially the same at different times and different depths of the monitoring points (Figure 12). The displacement fluctuated with different soil depth in the ZK1 monitoring point, and two wave peaks appeared in the soil depth of $0 \mathrm{~m}-35 \mathrm{~m}$. However, the value of displacement was minimal, that is, less than $0.1 \mathrm{~mm}$, between 2009 and 2012. In addition, a correlation relationship was not found between the displacements of 


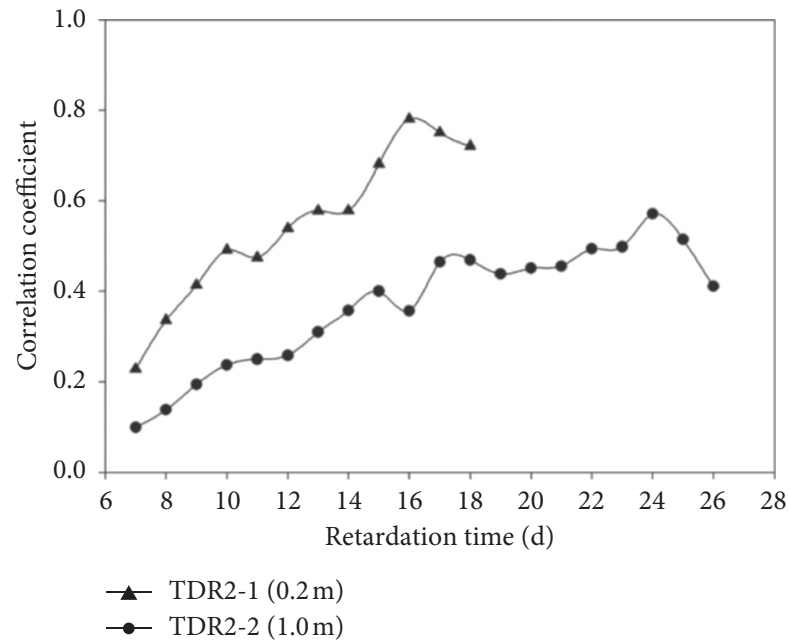

Figure 5: Correlation relationship between VWC and rainfall.

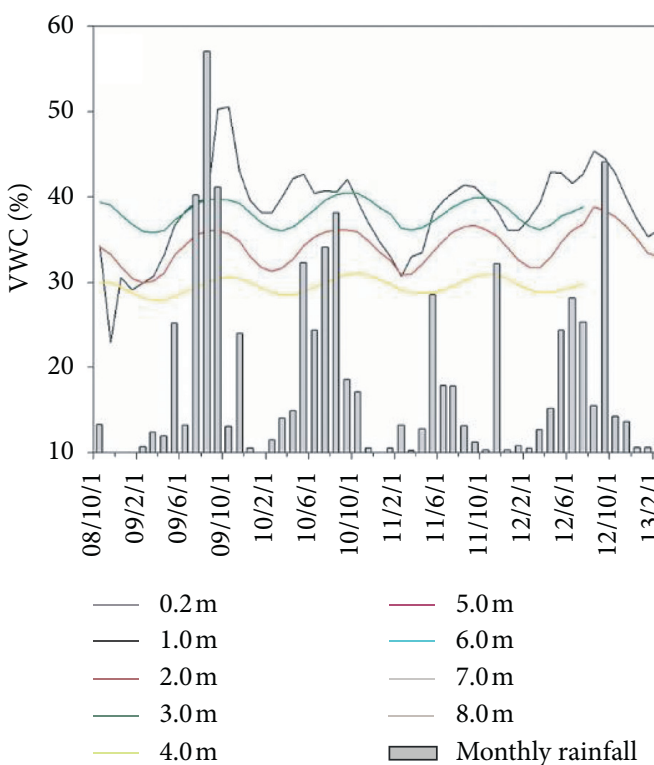

(a)

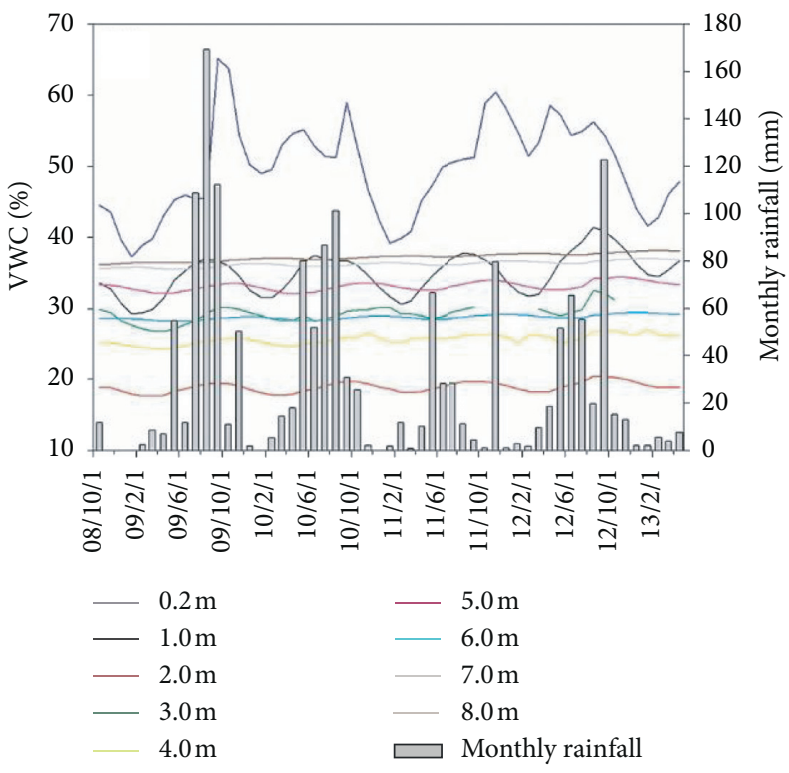

(b)

Figure 6: Continued. 

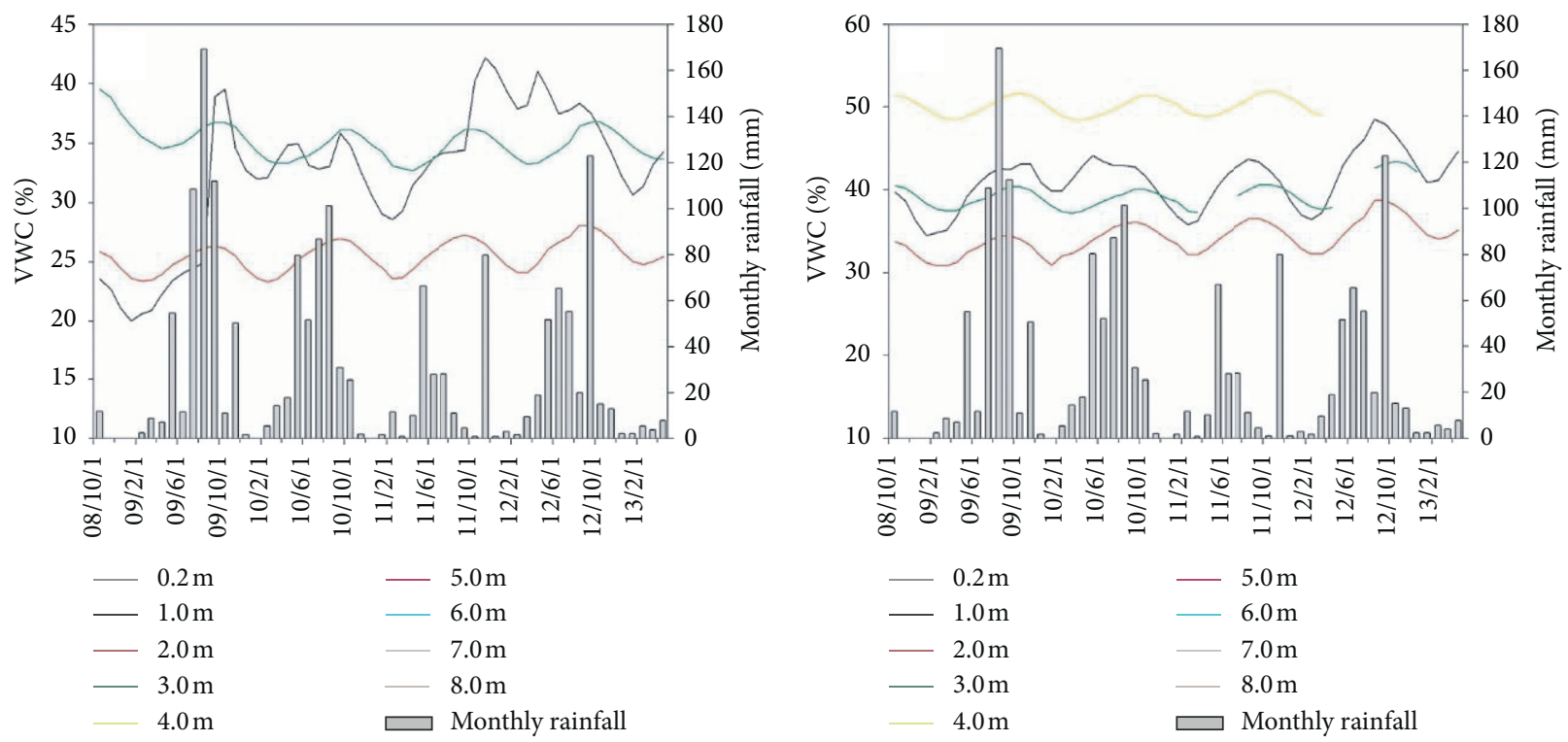

(c)

(d)

FIGURE 6: Relationship between monthly soil VWC and rainfall: (a) TDR1; (b) TDR2; (c) TDR3; (d) TDR4.

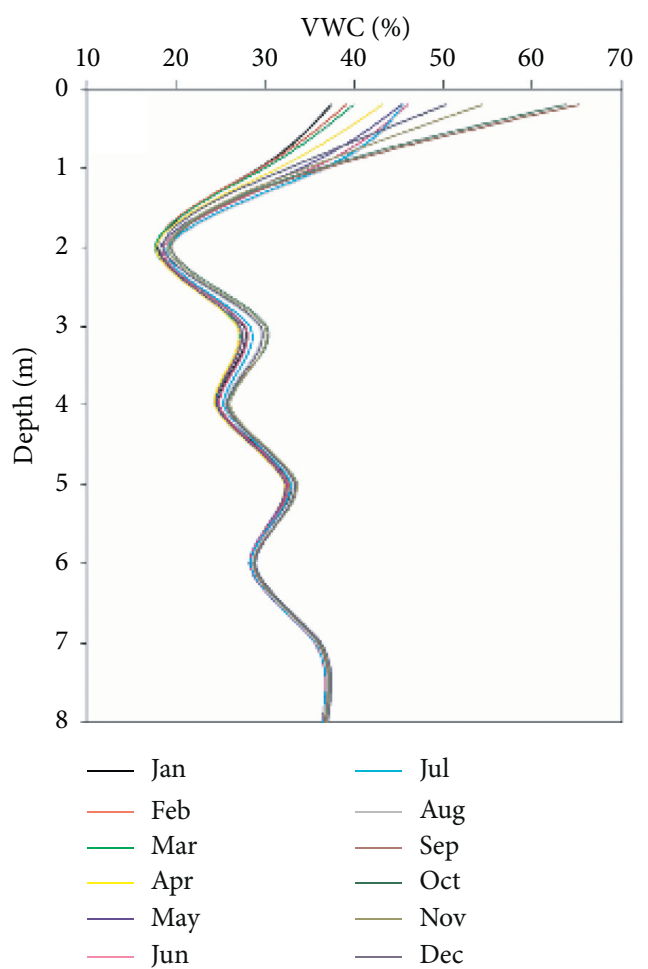

(a)

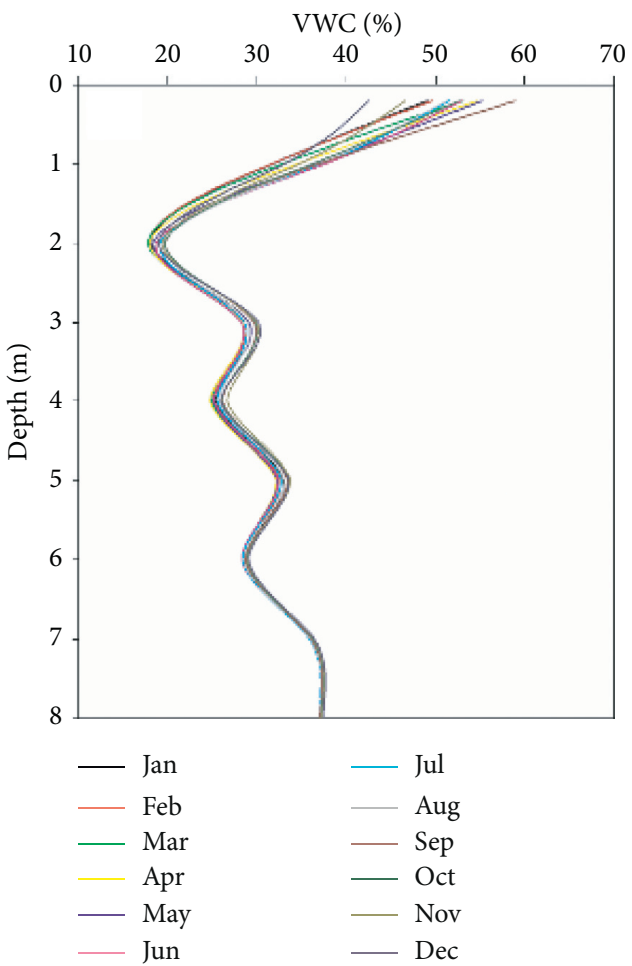

(b)

Figure 7: Continued. 


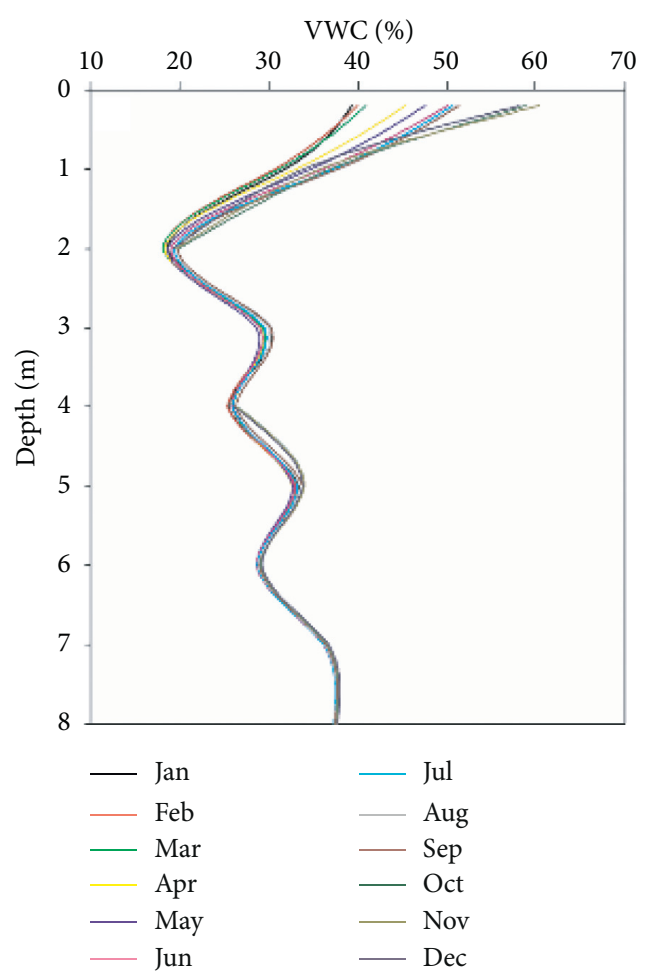

(c)

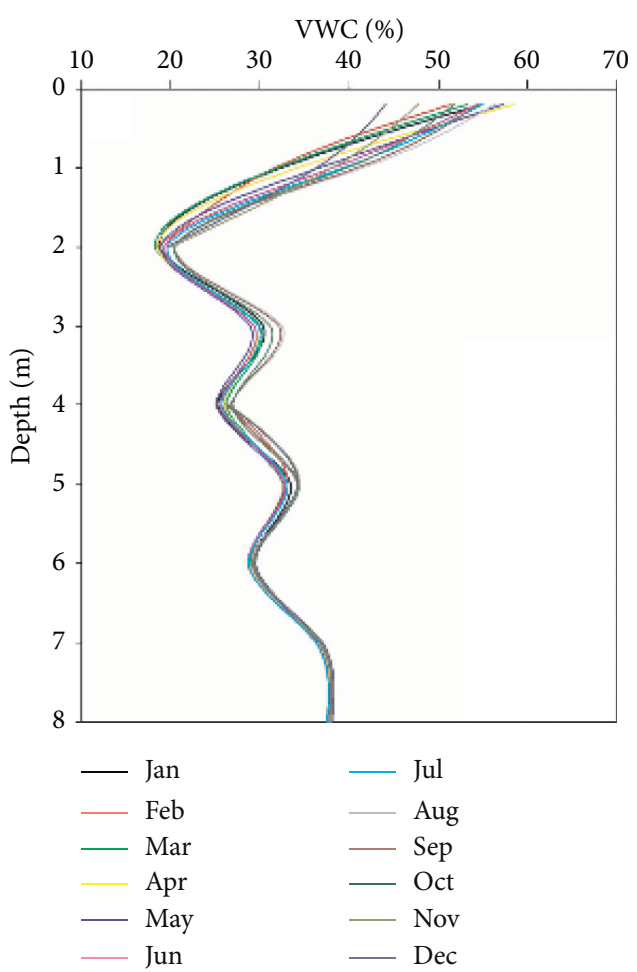

(d)

FIGURE 7: Relationship between VWC and different soil depth in different years on the TDR2 monitoring point: (a) 2009; (b) 2010; (c) 2011; (d) 2012. The other monitoring points data (DTR1, DTR3, and DTR4) are attached in supplementary files (Figures S1-S3).

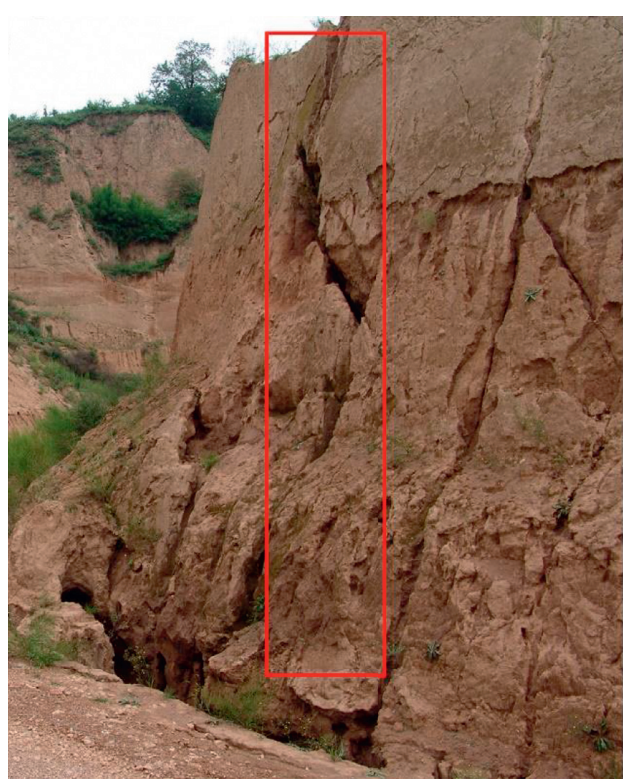

(a)

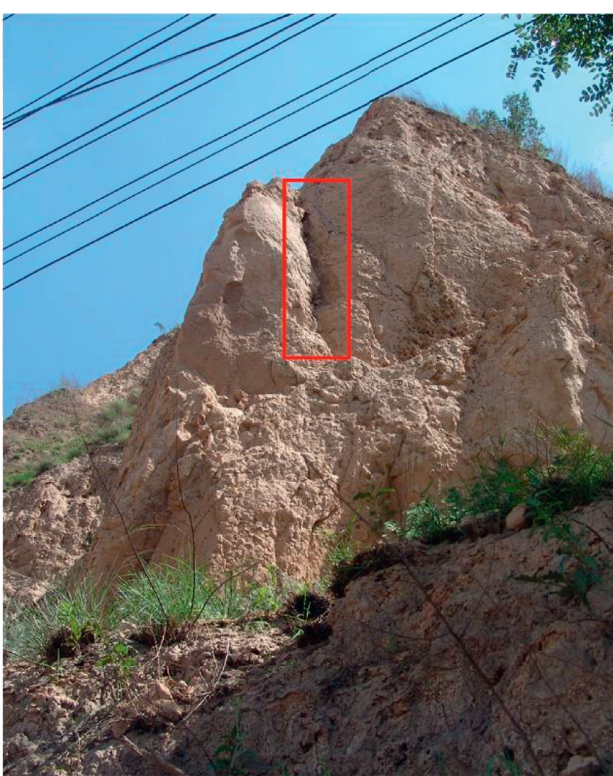

(b)

Figure 8: Cracks on Baota Mountain. 


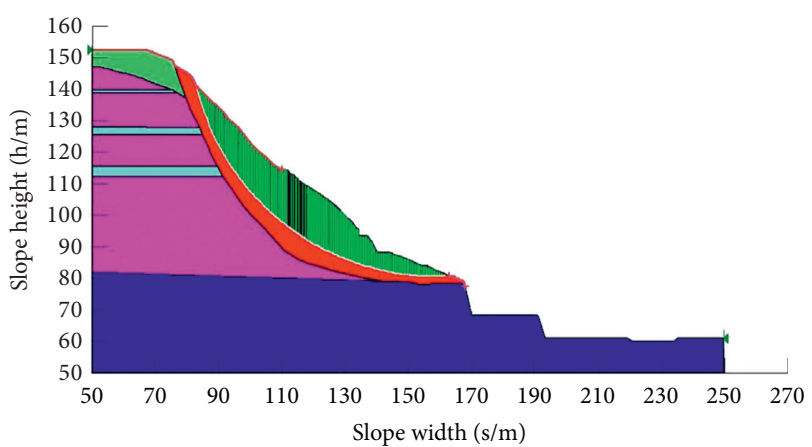

(a)

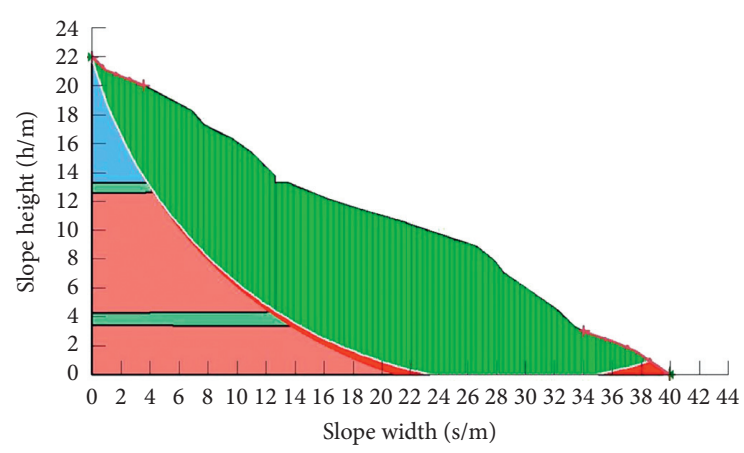

(b)

Figure 9: Landslide stability results of theoretical calculation: (a) landslide No. 1 (Fs=2.713); (b) landslide No. 2 (Fs=1.133).

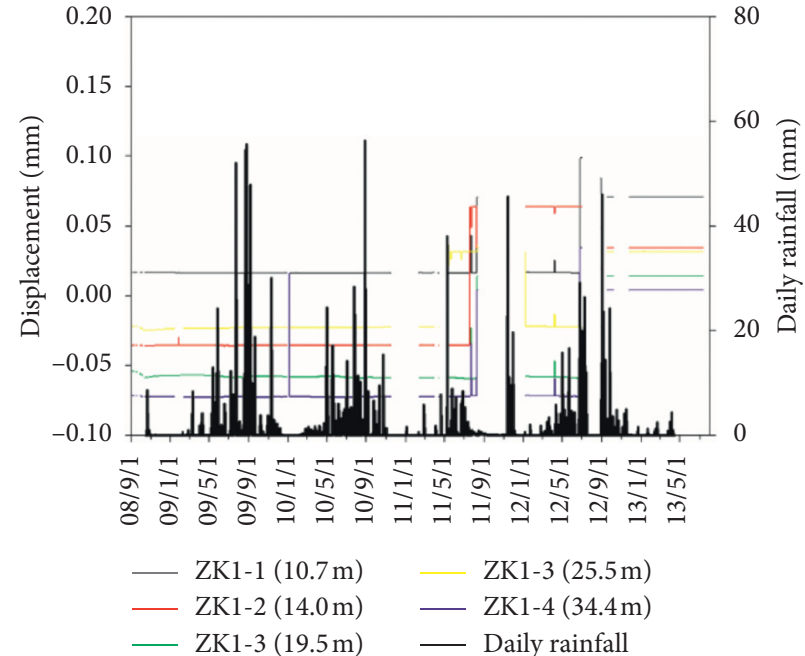

(a)

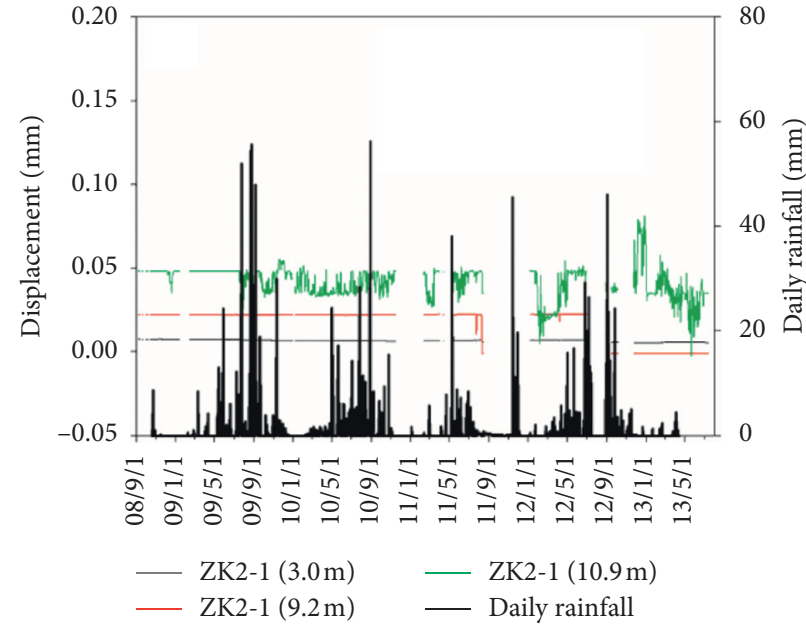

(b)

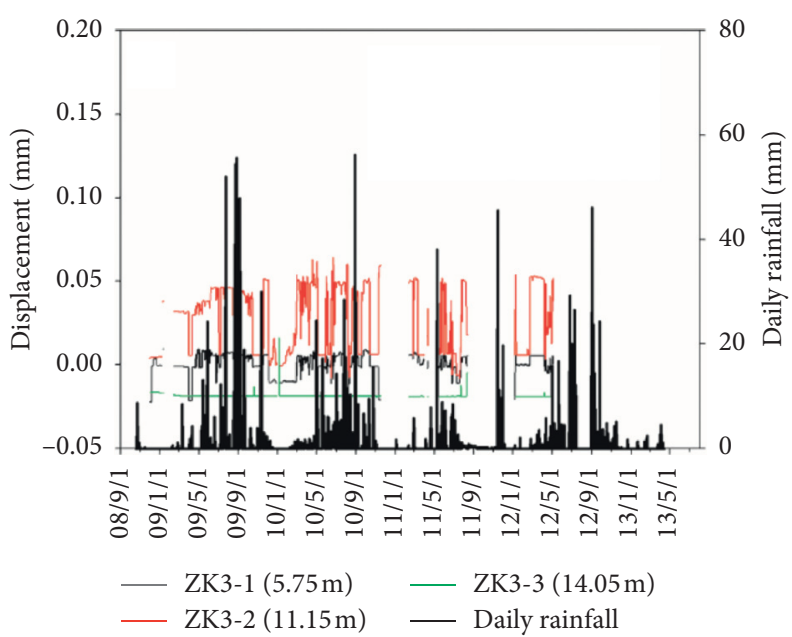

(c)

FIGURE 10: Relationship between daily landslide displacement and daily rainfall: (a) ZK1; (b) ZK2; (c) ZK3. 


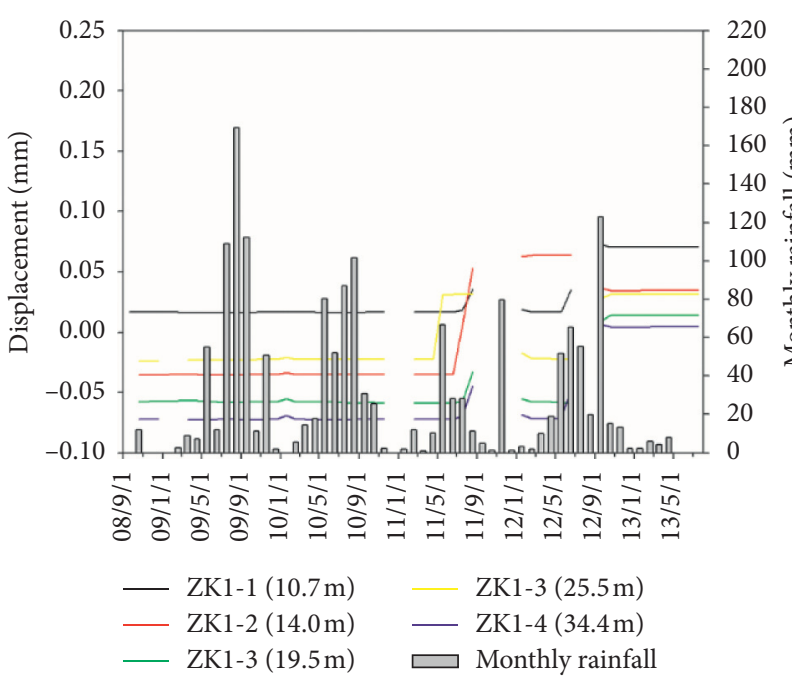

(a)

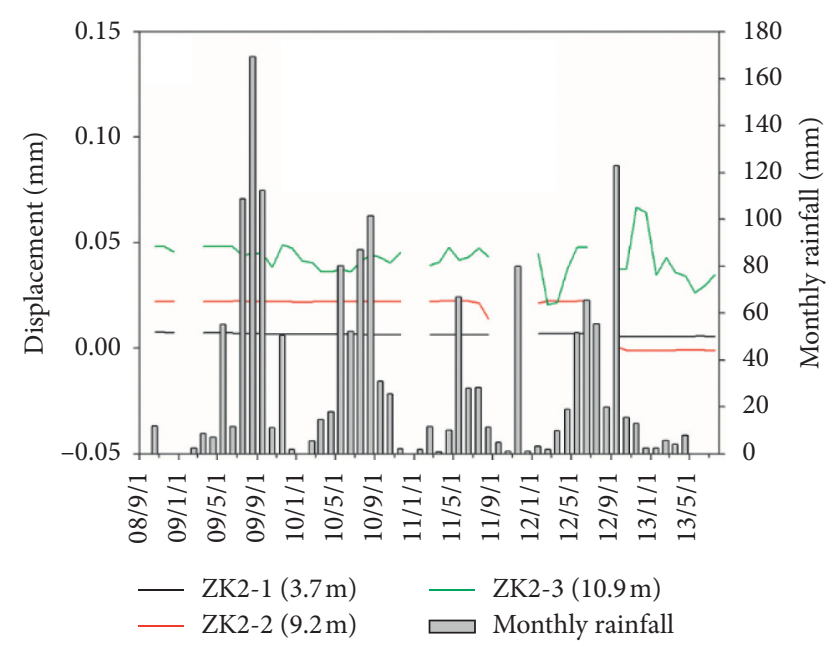

(b)

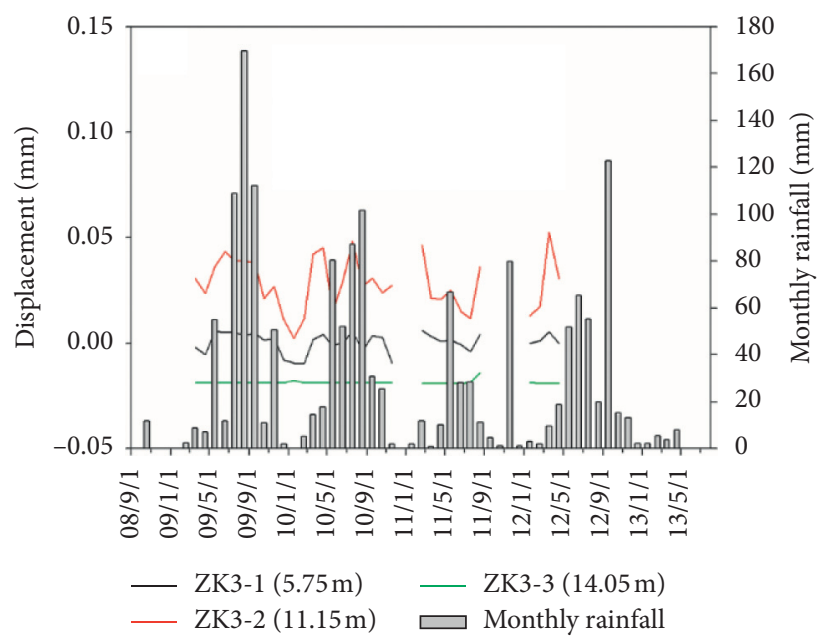

(c)

FIGURE 11: Relationship between monthly landslide displacement and monthly rainfall: (a) ZK1; (b) ZK2; (c) ZK3.

different depths and rainfall. These findings also indicated that landslide No. 1 was comparatively stable, and the results of the theoretical calculation were again verified to be accurate.

In general, the Baota Mountain landslide was stable, based on the results of monitoring data between 2008 and 2013. However, the closest distance was approximately $19 \mathrm{~m}$ between Baota and landslide No. 2. Moreover, a series of joints and fissures developed on the surface of the loess soils (Figure 8), and surface spalling always occurred. Shallow landslides will occur under the influence of continuous or heavy rainfall and once a landslide takes place, Baota would be threatened. This result was similar to the findings of other investigations [26]. Therefore, it is urgent to take certain protective measures to prevent Baota Mountain landslides.

\section{Conclusion}

Loess landslides are widely distributed across the loess regions of China, and landslide disasters are common due to heavy or continuous rainfall in this region. We applied field monitoring and limit equilibrium methods to estimate landslide stability.

The relationship between soil VWC and daily rainfall from October 2008 to March 2013 and the trends of VWC were similar in different years. Daily rainfall had an obvious 


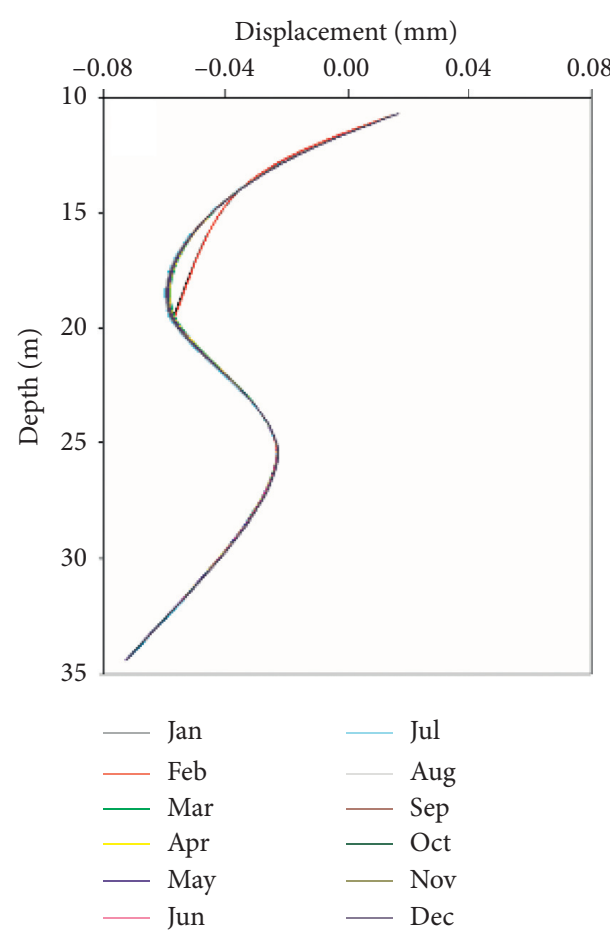

(a)

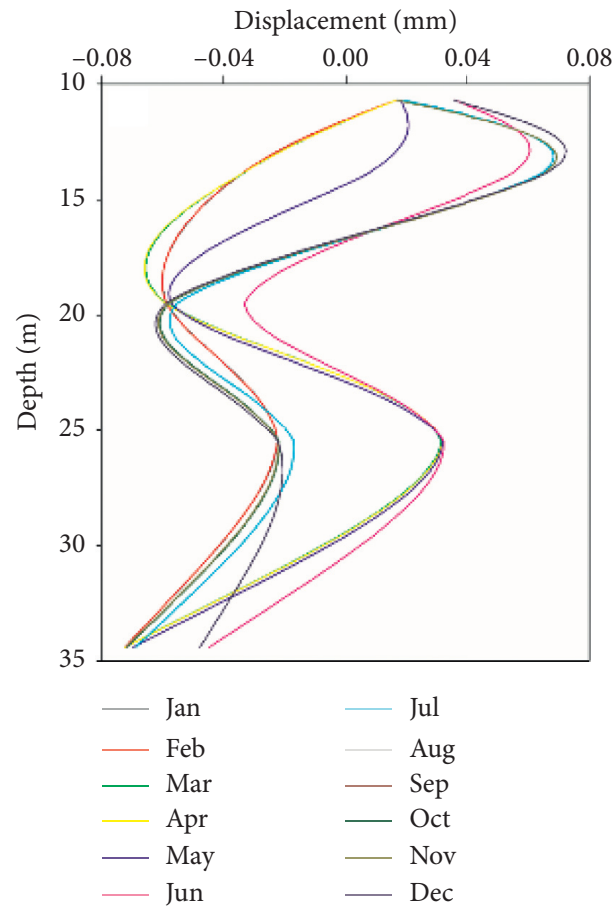

(c)

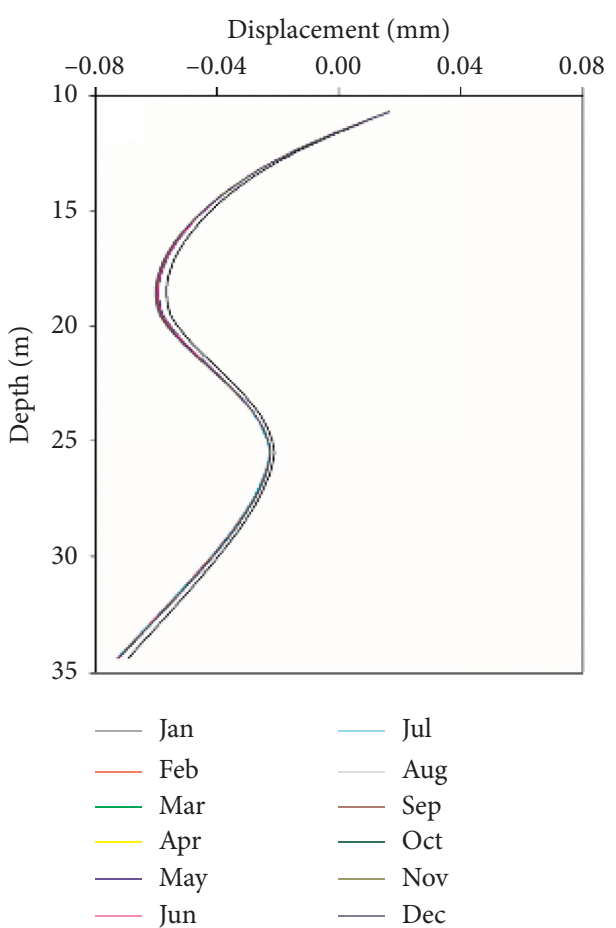

(b)

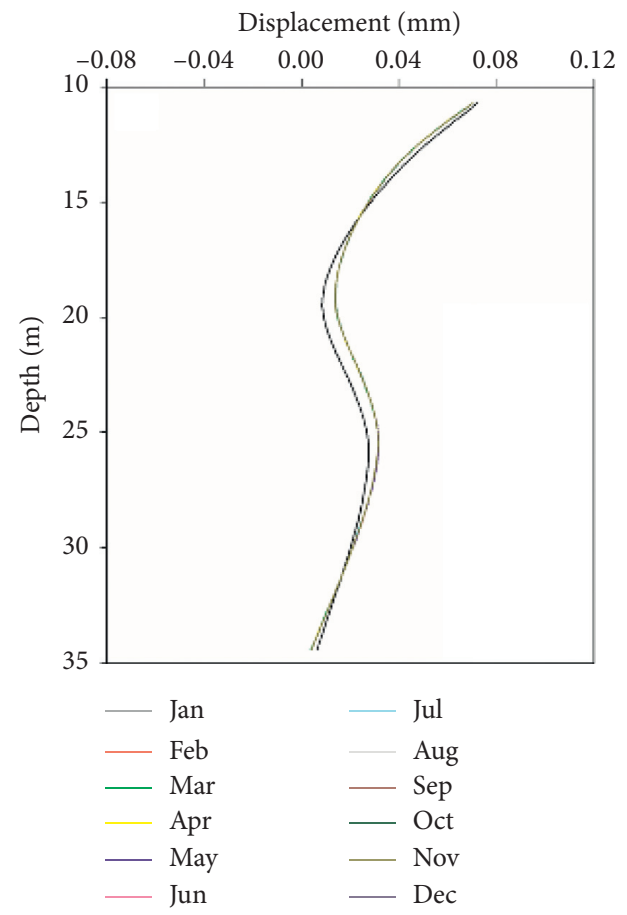

(d)

Figure 12: Relationship between landslide displacement and different soil depth in different years in the ZK1 monitoring point: (a) 2009; (b) 2010; (c) 2011; (d) 2012. The results of other monitoring points (ZK2 and ZK3) are attached in the supplementary files (Figures S4 and S5).

impact on VWC with the soil depth from $0 \mathrm{~m}$ to $1 \mathrm{~m}$. However, the VWC was stable when the soil depth was more than $2 \mathrm{~m}$. In addition, the VWC of surface soil $(0.2 \mathrm{~m})$ slightly increased when the daily rainfall was greater than $10 \mathrm{~mm}$; for the soil depth of $1 \mathrm{~m}$, however, the VWC was unchanged. VWC obviously increased above the soil depth of $1 \mathrm{~m}$ with daily rainfall of $50 \mathrm{~mm}$, while VWC was stable when the soil depth was more than $2 \mathrm{~m}$. Moreover, the retardation effect regarding VWC in different soil depths for rainfall was obvious. 
The Fs values were 2.713 and 1.133 for landslide No. 1 and landslide No. 2, respectively. This indicated that landslide No. 1 was relatively safe, while the probability of a landslide in landslide No. 2 was greater. The results of monitoring displacement indicated that landslide No. 1 was relatively stable between 2008 and 2013, which was consistent with the value of theoretical calculation.

\section{Data Availability}

The original data are available upon request.

\section{Conflicts of Interest}

The authors declare that they have no conflicts of interest.

\section{Acknowledgments}

This work was supported by the China Geological Survey Project (no. DD20190642).

\section{Supplementary Materials}

Figure S1: the relationship between VWC of soil and different soil depth under different years on the TDR1 monitoring point: (a) 2009; (b) 2010; (c) 2011; (d) 2012. Figure S2: the relationship between VWC of soil and different soil depth under different years on the TDR3 monitoring point: (a) 2009; (b) 2010; (c) 2011; (d) 2012. Figure S3: the relationship between VWC of soil and different soil depth under different years on the TDR4 monitoring point: (a) 2009; (b) 2010; (c) 2011; (d) 2012. Figure S4: the relationship between landslide displacement and different soil depth under different years on the ZK2 monitoring point: (a) 2009; (b) 2010; (c) 2011; (d) 2012. Figure S5: the relationship between landslide displacement and different soil depth under different years on the ZK3 monitoring point: (a) 2009; (b) 2010; (c) 2011; (d) 2012. (Supplementary Materials)

\section{References}

[1] C. H. Juang, T. Dijkstra, J. Wasowski, and X. Meng, "Loess geohazards research in China: advances and challenges for mega engineering projects," Engineering Geology, vol. 251, pp. 1-10, 2019.

[2] H. Shu, J. Ma, J. Guo, S. Qi, Z. Guo, and P. Zhang, "Effects of rainfall on surface environment and morphological characteristics in the Loess Plateau," Environmental Science and Pollution Research, vol. 27, no. 30, pp. 37455-37467, 2020.

[3] L. Lombardo, H. Tanyas, and I. C. Nicu, "Spatial modeling of multi-hazard threat to cultural heritage sites," Engineering Geology, vol. 277, Article ID 105776, 2020.

[4] Y. Jiao, D. Zhao, Y. Ding et al., "Performance evaluation for four GIS-based models purposed to predict and map landslide susceptibility: a case study at a World Heritage site in Southwest China," Catena, vol. 183, Article ID 104221, 2019.

[5] H. Shu, M. Hürlimann, R. Molowny-Horas et al., "Relation between land cover and landslide susceptibility in Val d'Aran, Pyrenees (Spain): historical aspects, present situation and forward prediction," Science of the Total Environment, vol. 693, 2019.
[6] C. Margottini, "Instability and geotechnical problems of the Buddha niches and surrounding cliff in Bamiyan valley, central Afghanistan," Landslides, vol. 1, no. 1, pp. 41-51, 2004.

[7] R. J. Marin and M. F. Velásquez, "Influence of hydraulic properties on physically modelling slope stability and the definition of rainfall thresholds for shallow landslides," Geomorphology, vol. 351, Article ID 106976, 2020.

[8] L. C. Li, C. A. Tang, W. C. Zhu, and Z. Z. Liang, "Numerical analysis of slope stability based on the gravity increase method," Computers and Geotechnics, vol. 36, no. 7, pp. 1246-1258, 2009.

[9] G. B. Crosta, S. Imposimato, and D. G. Roddeman, "Numerical modelling of large landslides stability and runout," Natural Hazards and Earth System Sciences, vol. 3, no. 6, pp. 523-538, 2003.

[10] A. Pourkhosravani and B. Kalantari, "A review of current methods for slope stability evaluation," Electronic Journal of Geotechnical Engineering, vol. 16, pp. 1245-1254, 2011.

[11] Y. Zhang, X. Hu, D. D. Tannant, G. Zhang, and F. Tan, "Field monitoring and deformation characteristics of a landslide with piles in the three Gorges reservoir area," Landslides, vol. 15, no. 3, pp. 581-592, 2018.

[12] L. Z. Wu, Y. Zhou, P. Sun, J. S. Shi, G. G. Liu, and L. Y. Bai, "Laboratory characterization of rainfall-induced loess slope failure," Catena, vol. 150, pp. 1-8, 2017.

[13] J. Xu, S. Wang, Z. Wang, L. Jin, and J. Yuan, "Heat transfer and water migration in loess slopes during freeze-thaw cycling in Northern Shaanxi, China," International Journal of Civil Engineering, vol. 16, no. 11, pp. 1591-1605, 2018.

[14] J. Xu and Z.-q. Wang, J.-w. Ren, S.-h. Wang, and L. Jin, Mechanism of slope failure in loess terrains during spring thawing," Journal of Mountain Science, vol. 15, no. 4, pp. 845-858, 2018.

[15] A. Zaki, H. K. Chai, H. A. Razak, and T. Shiotani, "Monitoring and evaluating the stability of soil slopes: a review on various available methods and feasibility of acoustic emission technique," Comptes Rendus Geoscience, vol. 346, no. 9-10, pp. 223-232, 2014.

[16] X. L. Yang and J. H. Yin, "Slope stability analysis with nonlinear failure envelopes," Journal of Rock Mechanics and Engineering, vol. 24, pp. 5896-5900, 2005.

[17] P. R. Tecca, A. Galgaro, R. Genevois, and A. M. Deganutti, "Development of a remotely controlled debris flow monitoring system in the Dolomites (Acquabona, Italy)," Hydrological Processes, vol. 17, no. 9, pp. 1771-1784, 2003.

[18] S. Uhlemann, A. Smith, J. Chambers et al., "Assessment of ground-based monitoring techniques applied to landslide investigations," Geomorphology, vol. 253, pp. 438-451, 2016.

[19] R. Vassallo, S. Calcaterra, N. D. Agostino et al., "Long-term displacement monitoring of slow earthflows by inclinometers and GPS, and wide area surveillance by COSMO-skymed data," Geosciences, vol. 10, no. 5, p. 171, 2020.

[20] J. S. Whiteley, J. E. Chambers, S. Uhlemann, P. B. Wilkinson, and J. M. Kendall, "Geophysical monitoring of moistureinduced landslides: a review," Reviews of Geophysics, vol. 57, no. 1, pp. 106-145, 2019.

[21] Z. Han, B. Su, Y. Li, Y. Ma, W. Wang, and G. Chen, "Comprehensive analysis of landslide stability and related countermeasures: a case study of the Lanmuxi landslide in China," Science Reports, vol. 9, pp. 1-12, 2019.

[22] X. Liu, Y. Wang, and D.-Q. Li, "Investigation of slope failure mode evolution during large deformation in spatially variable soils by random limit equilibrium and material point 
methods," Computers and Geotechnics, vol. 111, pp. 301-312, 2019.

[23] S. E. Cho, "Effects of spatial variability of soil properties on slope stability," Engineering Geology, vol. 92, pp. 97-109, 2007.

[24] M. F. Zolkepli, M. F. Ishak, and M. S. I. Zaini, "Slope stability analysis using modified Fellenius's and Bishop's method," IOP Conference Series: Materials Science and Engineering, vol. 527, pp. 1-12, 2019.

[25] Q. Xue, Y. M. Tang, P. P. Sun, and J. B. Bi, “Temporal-spatial distribution of soil water content in loess slope subjected to rainfall infiltration," Bulletin of Soil and Water Conservation, vol. 34, no. 2, pp. 53-56, 2014, (In Chinese).

[26] Q. Xue, M. S. Zhang, Y. M. Tang, and J. B. Bi, "Stability evaluation of the Baota mountain landslide based on deformation monitorin results," Hydrogeology and Engineering Geology, vol. 40, no. 3, pp. 110-114, 2013, (In Chinese).

[27] L. L. Zhang, J. Zhang, L. M. Zhang, and W. H. Tang, "Stability analysis of rainfall-induced slope failure: a review," in Proceedings of the Institution of Civil Engineers-Geotechnical Engineering, vol. 164, no. 5, pp. 299-316, 2011.

[28] A. W. Bishop, "The use of the slip circle in the stability analysis of slopes," Géotechnique, vol. 5, no. 1, pp. 7-17, 1955.

[29] E. Spencer, "Correspondence," Géotechnique, vol. 18, no. 1, pp. 92-93, 1968.

[30] J.-J. Wang, Y. Liang, H.-P. Zhang, Y. Wu, and X. Lin, "A loess landslide induced by excavation and rainfall," Landslides, vol. 11, no. 1, pp. 141-152, 2014.

[31] J. J. Wang, H. P. Zhang, and T. Liu, "Determine to slip surface in waterfront soil slope analysis," Advanced Materials Research, vol. 378-379, pp. 466-469, 2012.

[32] S. K. Sarma and D. Tan, "Determination of critical slip surface in slope analysis," Géotechnique, vol. 56, no. 8, pp. 539-550, 2006.

[33] J. Zhuang, J. Peng, G. Wang, I. Javed, Y. Wang, and W. Li, "Distribution and characteristics of landslide in Loess plateau: a case study in Shaanxi province," Engineering Geology, vol. 236, pp. 89-96, 2018.

[34] G. Chen, X. Meng, L. Qiao, Y. Zhang, and S. Wang, "Response of a loess landslide to rainfall: observations from a field artificial rainfall experiment in Bailong river basin, China," Landslides, vol. 15, no. 5, pp. 895-911, 2018.

[35] E. Derbyshire, "Geological hazards in loess terrain, with particular reference to the loess regions of China," EarthScience Reviews, vol. 54, no. 1-3, pp. 231-260, 2001.

[36] X. B. Tu, A. K. L. Kwong, F. C. Dai, L. G. Tham, and H. Min, "Field monitoring of rainfall infiltration in a loess slope and analysis of failure mechanism of rainfall-induced landslides," Engineering Geology, vol. 105, no. 1-2, pp. 134-150, 2009.

[37] R. Q. Zeng, X. M. Meng, F. Y. Zhan et al., "Characterizing hydrological processes on loess slopes using electrical resistivity tomography-a case study of the Heifangtai Terrace, Northwest China," Journal of Hydrology, vol. 541, pp. 742$753,2016$.

[38] Y. Okura, H. Kitahara, H. Ochiai, T. Sammori, and A. Kawanami, "Landslide fluidization process by flume experiments," Engineering Geology, vol. 66, no. 1-2, pp. 65-78, 2002.

[39] S. Segoni, L. Piciullo, and S. L. Gariano, "A review of the recent literature on rainfall thresholds for landslide occurrence," Landslides, vol. 15, no. 8, pp. 1483-1501, 2018.

[40] G. Sorbino and M. V. Nicotera, "Unsaturated soil mechanics in rainfall-induced flow landslides," Engineering Geology, vol. 165, pp. 105-132, 2013.
[41] M. Bordoni, C. Meisina, R. Valentino, N. Lu, M. Bittelli, and S. Chersich, "Hydrological factors affecting rainfall-induced shallow landslides: from the field monitoring to a simplified slope stability analysis," Engineering Geology, vol. 193, pp. 19-37, 2015.

[42] F. Salmasi, B. Pradhan, and B. Nourani, "Prediction of the sliding type and critical factor of safety in homogeneous finite slopes," Applied Water Science, vol. 9, pp. 1-11, 2019. 